\title{
Modelling the biphasic growth of non-starter lactic acid bacteria on starter-lysate as a substrate
}

\author{
Møller, C.O. de A.; Christensen, B. B.; Rattray, F.P.
}

Published in:

International Journal of Food Microbiology

Link to article, DOI:

10.1016/j.ijfoodmicro.2020.108937

Publication date:

2021

Document Version

Peer reviewed version

Link back to DTU Orbit

Citation (APA):

Møller, C. O. D. A., Christensen, B. B., \& Rattray, F. P. (2021). Modelling the biphasic growth of non-starter lactic acid bacteria on starter-lysate as a substrate. International Journal of Food Microbiology, 337, [108937]. https://doi.org/10.1016/j.ijfoodmicro.2020.108937

\section{General rights}

Copyright and moral rights for the publications made accessible in the public portal are retained by the authors and/or other copyright owners and it is a condition of accessing publications that users recognise and abide by the legal requirements associated with these rights.

- Users may download and print one copy of any publication from the public portal for the purpose of private study or research.

- You may not further distribute the material or use it for any profit-making activity or commercial gain

- You may freely distribute the URL identifying the publication in the public portal 


\section{Journal Pre-proof}

Modelling the biphasic growth of non-starter lactic acid bacteria on starter-lysate as a substrate

C.O. de A. Møller, B.B. Christensen, F.P. Rattray

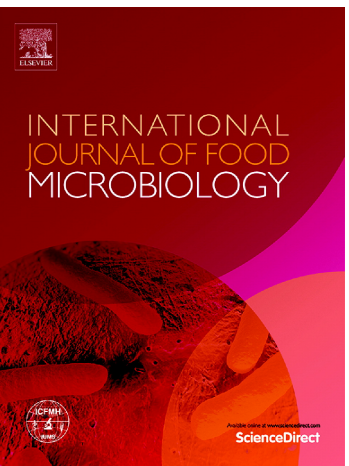

PII: $\quad$ S0168-1605(20)30431-1

DOI: $\quad$ https://doi.org/10.1016/j.ijfoodmicro.2020.108937

Reference: $\quad$ FOOD 108937

To appear in: $\quad$ International Journal of Food Microbiology

Received date: $\quad 30$ May 2020

Revised date: $\quad 11$ September 2020

Accepted date: $\quad 11$ October 2020

Please cite this article as: C.O.d.A. Møller, B.B. Christensen and F.P. Rattray, Modelling the biphasic growth of non-starter lactic acid bacteria on starter-lysate as a substrate, International Journal of Food Microbiology (2020), https://doi.org/10.1016/ j.ijfoodmicro.2020.108937

This is a PDF file of an article that has undergone enhancements after acceptance, such as the addition of a cover page and metadata, and formatting for readability, but it is not yet the definitive version of record. This version will undergo additional copyediting, typesetting and review before it is published in its final form, but we are providing this version to give early visibility of the article. Please note that, during the production process, errors may be discovered which could affect the content, and all legal disclaimers that apply to the journal pertain.

(C) 2020 Published by Elsevier. 


\title{
Modelling the biphasic growth of non-starter lactic acid
}

\section{bacteria on starter-lysate as a substrate}

\author{
C.O. de A. Møller ${ }^{1 *}$, B.B. Christensen ${ }^{1,2}$, F.P. Rattray ${ }^{1}$ \\ ${ }^{1}$ University of Copenhagen, Department of Food Science, Section of Microbiology and Fermentation, Rolighedsvej 26, DK-1958 \\ Frederiksberg, Denmark \\ ${ }^{2}$ Technical University of Denmark, DTU BIOENGINEERING, Institute of Biotechnology and Biomedicine, Søltofts Plads, Bygning 221 , \\ DK-2800 Kgs. Lyngby, Denmark \\ "Correspondent author: cleide@food.ku.dk
}

\begin{abstract}
Since cheese is poor in energy for bacterial grr $v v^{h}$, it is believed that non-starter lactic acid bacteria growth and flavour develop ${ }^{2 . . .} n_{\mathrm{t}}$ эre supported by the nutrients from lysis of the starter culture. This study was performe 1 to investigate the dynamics of interaction between starter and non-starter strø,n, frum cheese. A starter culture lysate was prepared by enzymatic digestion and testc $\gamma$ as a growth substrate for Lactobacillus sp. strains. The two starter culture strains of La tucoccus lactis were also tested on the starter-lysate. All seventeen strains were ir divı yually inoculated at the level of $5.0 \log _{10} \mathrm{cfu} \mathrm{mL}^{-1}$ in M17 broth, with or without $10 \%$ starter-lysate, and incubated at $30{ }^{\circ} \mathrm{C}$ for $140 \mathrm{~h}$. The optical density $_{600 \mathrm{~nm}}$ was modelled with the primary log-transformed Logistic model with delay and lag phase duration, maximum specific growth rate as well as maximum population density obtained. Biphasic growth was mainly observed when the strains were able to utilize the starter-lysate as an energy source. To deal with the lack-of-fit related to the biphasic growth, the observed data points of the curve were divided after graphic evaluation and according to deviation of the residuals from the range \pm 0.05 . Modelling was then
\end{abstract}


performed in two phases by applying the same primary Logistic model in each of the two parts of the growth curve. Values of root-mean-square error and graphic evaluation indicated the good fitting of the data with the suggested approach. The growth of the two Lactococcus lactis strains was not affected by the starter-lysate. However, thirteen of the non-starter strains had their growth rates increased. The increase was greatest for Lactobacillus rhamnosus KU-LbR1, which reached maximum optical densities of 0.23 and 0.58 in the absence and the presence of starter-lysate, respintively. No effect of the starter-lysate was shown for the growth of Lactobacillus $\mathrm{CL}^{\text {rval }}$ is strains. The extend of the growth of non-starter strains on the starter-lysate $v a_{i} c^{\prime}$ own to be species and strain dependent.

Keywords: Lactobacillus; Lactococcus; b^+eı il interaction; enzymatic digestion; cheese isolates; biphasic model 


\section{Introduction}

The microbial ecology of cheese involves a rich and complex interaction between the starter lactic acid bacteria (SLAB) and the non-starter lactic acid bacteria (NSLAB). The SLAB in the cheese decline throughout ripening while growth of NSLAB increases as ripening progresses (Gantzias et al., 2020; Mugampoza et al., 2020; Settanni and Moschetti, 2010).

While Lactococcus lactis serves as the starter lactic acid bac ${ }^{+}$ria (SLAB) for the manufacture of many cheese types, Lactobacilli constitute he najority of NSLAB in long time ripened cheeses (Broadbent et al., 2013; Calassc $\epsilon^{\prime}{ }^{2}{ }^{\prime}$., 2020; Gobbetti et al., 2015). The NSLAB, mainly originating from raw milk and/c fro $n$ the environment, contribute to the final characteristics of the cheese (Alessar л $а$ et al., 2016; de Pasquale et al., 2019; Saidi et al., 2020). The main NSLAB speris s redominating in cheese are Lactobacillus casei, Lactobacillus plantarum, and Lactow: $: i l l u s$ brevis. Typical NSLAB cell densities in cheeses such as Cheddar cheese $r_{10} y^{\circ}$, Irom 10 to $10^{4} \mathrm{cfu} \mathrm{g}^{-1}$ during the first 5-10 days ripening and increase to about $1 a^{1,7}$ to $10^{8} \mathrm{cfu} \mathrm{g}^{-1}$ after a few months ripening. Lactobacilli in cheese grow on the amino acli' released from enzymatic hydrolysis of casein, as well as on the cell contents of the ste ter bacteria. NSLAB are tolerant to $\mathrm{pH}$ values as low as 4.9 , salt up to $6 \%$ and a wida ' ange of temperature $\left(2-53 C^{\circ}\right)$ conditions (Gobbetti et al., 2015; Montel et al., 2014; Pangallo et al., 2019; Peterson and Marshall, 1990; Wouters et al., 2002).

The importance of autolysis of the starter lactic acid bacteria in cheese ripening is evident from the literature. This concept of cannibalism of SLAB by NSLAB was proposed by Thomas (1987) and it has been shown in other studies investigating the effect of sugars and amino acids in supporting NSLAB growth (Adamberg et al., 2005; Møller et al., 2020; 
Ortakci et al., 2015; Saidi et al., 2020; Wallace and Fox, 1997). Czarán et al. (2018) suggested that the concentration of nutrients released from SLAB is an important factor influencing the rate of NSLAB growth during cheese ripening.

This study was performed in order to investigate the dynamics involved in the bacterial interaction between SLAB lysis and NSLAB growth using an in vitro model to simulate the conditions found during Cheddar cheese ripening. A starter-lysate prepared from a starter culture was investigated as a growth substrate for different I'SLAB strains. The effect of the starter-lysate was modelled and evaluated, in order to :et : better understanding of the mechanisms as well as generating insights for imp 0 .in' and accelerating cheese ripening. 


\section{Material and Methods}

\subsection{Starter-lysate preparation}

A mesophilic homofermentative culture, type $\mathrm{O}$, containing a combination of Lactococcus lactis subsp. cremoris and Lactococcus lactis subsp. lactis (Frozen-Direct Vat Set (F-DVS) of R-607, Chr. Hansen S/A, Hørsholm, Denmark) was used for preparation of the starterlysate. The starter-lysate was obtained by enzymatic digestion of the starter culture applying treatment with lysozyme, phospholipase, proteinas: DNAse and RNAse. This protocol was designed to release of $\mathrm{N}$-acetylmuramic acid, $\mathrm{N}-\varepsilon$ setylglucosamine and amino acids from the cell wall, and ribose as well as n'icinir acids from DNA and RNA. The starter culture $(500 \mathrm{~g})$ was melted and centriff:' 'ed ' $6,000 \mathrm{xg}$ ) for 10 min at $4{ }^{\circ} \mathrm{C}$. The supernatant was discarded, and the initial volu' it was reached again by adding a $0.9 \%$

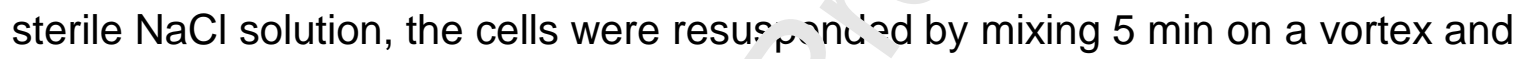
centrifuged $\left(6,000 \times \mathrm{g}\right.$ for $10 \mathrm{~min}$ at $\left.4^{\circ} \mathrm{C}\right)$. ine same procedure was performed three times and finally a $0.03 \mathrm{M}$ sterile Tris- $\mathrm{HCl}$ \& $\approx$ ma-Aldrich, Copenhagen, Denmark) buffer ( $\mathrm{pH}$ 8.0) was added ( $8.33 \mathrm{~mL} \mathrm{~g}$ pelle! $\left.{ }^{2}\right)$. . fter supplementing with $0.3 \mathrm{mg} \mathrm{mL}^{-1}$ lysozyme (Sigma-Aldrich) and $5.0 \mu \mathrm{g} \mathrm{mL}^{-1}$ phospholipase (Sigma-Aldrich), a three hours incubation took place with slow shal ing at $37^{\circ} \mathrm{C}$. Subsequently, $6.0 \mu \mathrm{gL}^{-1} \mathrm{DNAse}$ (Sigma-Aldrich) and $28 \mu \mathrm{g} \mathrm{mL}^{-1}$ RNAse (S'yma-Aldrich) were added and the described incubation with shaking at $37^{\circ} \mathrm{C}$ for $2.5 \mathrm{~h}$. Finally $75 \mu \mathrm{g} \mathrm{mL}{ }^{-1}$ proteinase $\mathrm{K}$ (Sigma-Aldrich) was added and the sample incubated at $37^{\circ} \mathrm{C}$ for $14 \mathrm{~h}$, and then heated at $80^{\circ} \mathrm{C}$ for 30 min to inactivate the enzymes. After a last centrifugation step $\left(6,000 \times \mathrm{g}\right.$ for 30 min at $\left.4{ }^{\circ} \mathrm{C}\right)$, the supernatant was stored at $-20^{\circ} \mathrm{C}$ and designated as "starter-lysate". This starter-lysate was analysed for sugars and amino acids content. Determination of sugars was performed by HPLC High Performance Liquid Chromatograph (Lloyd, 2008) and the most relevant sugar was 
analysed with enzymatic assay (Megazyme, Co. Wicklow, Ireland), according to the manufacture's instructions. Amino acids content in the starter-lysate was obtained with UPLC - Ultra Performance Liquid Chromatograph (Møller et al., 2020).

\subsection{Lactic acid bacteria strains and inoculum preparation}

Fifteen non-starter lactic acid bacteria (NSLAB) were investigated and included $L b$. brevis CCUG $30670^{\top}$, Lb. casei subsp. lactis DSM $20011^{\top}$, Lb. cor 'riformis CCUG $30666^{\top}$, Lb. curvatus DSM $20019^{\top}$, Lb. curvatus CCUG $30669^{\top}$, Lb. de. hru 'ckii subsp. bulgaricus DSM $20081^{\top}$, Lb. delbrueckii subsp. delbrueckii CCUG 342؟厃2 ${ }^{\top}$ I J. fermentum DSM $20052^{\top}$, Lb. helveticus CCUG $30139^{\top}$, Lb. parabuchneri DSM $2105^{\top \top}$, Lb. paracasei NCFB $151^{\top}$, Lb. plantarum subsp. plantarum ATCC $14917^{\top}$, Lb riamnosus DSM $20021^{\top}$ ), as well as $L b$. casei $\mathrm{KU}-\mathrm{LbC1}$ and $\mathrm{Lb}$. rhamnosus $\mathrm{KU}-\mathrm{L}$ ',$? 1$; isolated in this study from a vintage Cheddar cheeses according to the methoa ?pplied by Møller et al. (2020)). In addition, the two strains of starter lactic acid bacter l $^{\prime}(\mathrm{SLAB})$, isolated from the starter culture R-607 (Lactococcus lactis subsp. crem; ris and Lactococcus lactis subsp. lactis) were also investigated. The inoculum of $\iota^{{ }^{7} \mathrm{C} n}$ of the $15 \mathrm{NSLAB}$ and the two starter culture representatives were nre, ar $\_x$ individually. Stocks of the isolates (kept in $20 \%$ glycerol at $-81^{\circ} \mathrm{C}$ ) were thawed, mixf $\mathrm{d}$ and $100 \mu \mathrm{L}$ transferred to $10 \mathrm{~mL}$ media in $50 \mathrm{~mL}$ tubes, and incubated for $24 \mathrm{~h}$, applying conditions for Lactobacillus (MRS broth at $30^{\circ} \mathrm{C}$ ) and Lactococcus (M17 broth with lactose at $\left.25^{\circ} \mathrm{C}\right)$ (OXOID, Hampshire, England). One $\mathrm{mL}$ of the grown culture was centrifuged $\left(6,000 \times \mathrm{g}\right.$ for $10 \mathrm{~min}$ at $\left.4^{\circ} \mathrm{C}\right)$ and the pellet with the cells was resuspended, washed with an equal volume of $0.9 \% \mathrm{NaCl}$, and centrifuged $\left(6,000 \times \mathrm{g}\right.$ for $10 \mathrm{~min}$ at $\left.4^{\circ} \mathrm{C}\right)$. The washed, diluted culture was then used as an inoculum for the growth experiments. 


\subsection{Growth experiments}

Growth experiments were performed in microtiter plates with a total volume of $250 \mu \mathrm{L}$ in each well. The strains were individually inoculated (about $5.0 \log _{10} \mathrm{cfu} \mathrm{mL} \mathrm{m}^{-1}$ ) in $\mathrm{M} 17$ broth (no lactose added), with or without $10 \%$ starter-lysate $(\mathrm{v} / \mathrm{v})$, and incubated at $30{ }^{\circ} \mathrm{C}$ for $140 \mathrm{~h}$. To avoid evaporation the surface of the wells was covered with sterile filtrated paraffin oil. The same experimental design was applied in a - 2 cond trial, in which an inoculation level of $7.0 \log _{10} \mathrm{cfu} \mathrm{\textrm {mL } ^ { - 1 }}$ was used. In a third t ial he starter-lysate was also tested at the level of $33 \%(\mathrm{v} / \mathrm{v})$ in $\mathrm{M} 17$ broth containin $\mathrm{j}_{\mathrm{f}}$ \% $\mathrm{NaCl}(\mathrm{v} / \mathrm{v})$, in order to simulate the salt-in-moisture level in Cheddar che€:e. 'riplicates of negative control (noninoculated media) and of each of the tested co' iv 'ions was monitored with an absorbance

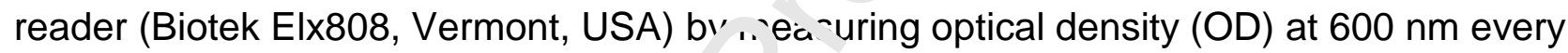
hour. Microtiter plate were shaken for 30 st -onds prior to reading. 


\subsection{Modelling}

To evaluate the impact of the tested conditions on the stages of the bacterial life cycle, it was essential to apply appropriate primary modelling. Therefore, the primary logtransformed Logistic model with delay (Dalgaard, 2009) was selected. Before fitting of the observed data, the average of the optical density measured in triplicate at $600 \mathrm{~nm}$ was multiplied by 10,000 and log transformed. By applying the Excel solver function, lag phase duration (h), maximum specific growth rate $\left(\mu \mathrm{max}, \mathrm{h}^{-1}\right)$ and 1. ?ximum population density (Nmax, $\left.\mathrm{OD}_{600 \mathrm{~nm}}\right)$ were then obtained. A new modelling apk roar $\mathrm{h}$ was also proposed, to deal with the lack of fit, believed to be related to the $n t^{t} n_{n} n^{+}$limited conditions. Details of the alternative modelling approach are described in the Results and Discussion (Section 3.2.2).

\subsection{Data analysis}

Graphic evaluation and values of $R^{\prime}$ ハ:: ! Root-Mean-Square Error) were used to evaluate the quality of the modelling fits, i: relation to the observed growth of the strains (Møller et al., 2016). Good graphic evaluction and low values of RMSE were considered for selecting the most appropriate valı es if lag phase duration, $\mu$ max and Nmax. Student's paired $t$-test was applied to identify if $d$.ferences in these values were significant at the level of $0.05 \%$, using R studio software (Version3.6.1), and the effect of the starter-lysate on the growth phases of the tested strains was investigated.

Acceptable Simulation Zone (ASZ) suggested by Oscar (2005) was applied as described by Møller et al. $(2013 ; 2016)$ to evaluate the quality of the simulations obtained by applying the parameters from the modelling approach in a dataset different from that used in the fittings. According to Møller et al. (2013) and Velugoti et al. (2011) a deviation of \pm 0.5 
$\log _{10} \mathrm{cfu} \mathrm{mL} \mathrm{L}^{-1}$ between the observed and simulated values is acceptable. Therefore, the $\log _{10} \mathrm{OD}_{600}$ variance between datasets with $\mathrm{Nmin}$ within $0.5 \log _{10}$ cfu $\mathrm{mL}^{-1}$ difference $( \pm$ $0.14 \log _{10} \mathrm{OD}_{600}$ ) was used to create the ASZ. For practical reasons and to avoid large deviation between the first and the second phase of the suggested two-phases Logistic approach, a baseline was used to correct the $2 \log _{10} \mathrm{CFU} \mathrm{mL}{ }^{-1}$ difference between the fitted and simulated dataset. This baseline correction was performed by the addition of 0.37 to each of the simulated data points (which is the perce? $?^{+}$ual difference of Nmin between the two datasets). 


\section{Results and Discussion}

\subsection{Graphic evaluation of the effect of starter-lysate}

Not surprisingly, none of the two SLAB representatives (Lactococcus lactis subsp.

cremoris and Lactococcus lactis subsp. lactis) was affected by the addition of the starterlysate to the medium, as shown in Figure 1. On the other hand, 13 of the tested NSLAB had increased growth when starter-lysate was added. Accos *ing to Figure 2, a similar effect of starter-lysate addition on growth pattern of the tes ed JSLAB was shown between: 1) Lb. casei KU-LbC1 (C) and Lb. rhamnosu;' 'I LbR1 (O); 2) Lb. coryniformis CCUG 30666 (D), Lb. delbrueckii subsp. bulgaricu: DS V 20081 ${ }^{\top}$ (G), and Lb. delbrueckii subsp. delbrueckii CCUG $34222^{\top}(\mathrm{H})$; 3) Lb. hr iv sticus CCUG $30139^{\top}(\mathrm{J})$ and Lb. plantarum subsp. plantarum ATCC $1491^{-\top}$ ' $\mathrm{N}_{1}^{\prime}$, and 4) Lb. parabuchneri DSM $20057^{\top}(\mathrm{K})$ and $L$ b. paracasei NCFB $151^{\top}(\mathrm{L})$. Starter-ı, sate seem to have no effect on growth of the Lb. curvatus strains ( $E$ and F). Desr itt, the effect of the addition of the starter-lysate, shown on growth of most of the vesigated $L A B$, more than visual inspection of the growth curves was required to avaluate the dimension of this effect. Before performing this detailed analysis, modelling $\mathrm{f} f$ the observed data was performed. The modelling makes the data comparable and: Ilows investigation of the effect of the starter-lysate at each stage of the growth curves. 
3.2 Modelling approach development

\subsubsection{Fitting with the log-transformed Logistic model with delay}

To allow a more detailed investigation of the starter-lysate addition, the log-transformed data for the 17 strains was initially fitted with the primary log-transformed Logistic model with delay (Dalgaard, 2009). As indicated with the high RMSE values (Table 1, RMSE (1)) and also exemplified in Figures 3A, 3C and 3E, the lack-of- $f_{1}{ }^{\prime}$ ' was observed for most of the investigated growth curves, when applying the simple log- $t$ ans formed logistic model with delay to the observed growth curves. Visual inspectior $c$ th $^{\text {th }}$ curves when fitted to the simple log-transformed logistic model clearly indice ed hat the lack of fit was due to a biphasic growth behaviour.

The challenges in modelling biphasic gre:vi 1 , ?s been reported by Guerra et al. (2010) when investigating Enterococcus faecium ı. realkalized fed-batch fermentations in whey, and many attempts have been sugş $25 ;$ in to overcome the lack-of-fit when applying traditional primary models to des ·rib€ biphasic growth. As reported by Wilson et al. (2017) such models can improve the waerstanding of the life cycle of microorganisms, however it can be more complicatec' to I se than conventional growth models, due to the need for high amounts of data, mill.jple growth phases and increased parameterization. 


\subsubsection{Dealing with the lack-of-fit}

As suggested by Guerra et al. (2010) and Meyer (1994), in the case of biphasic growth, the most appropriate modelling approach is based on the sum of two simple growth phases. In search for a practical but an efficient and meaningful solution, a two-phases Logistic modelling approach is proposed in the present study.

The first step of the proposed two-phases Logistic modelling approach was to analyze the curves fitted with the one phase approach (Figures $3 A, 3 C a^{n} \sqrt{ } 3 \mathrm{E}$ ). By graphic evaluation and considering the data point when consistent deviation $c$ ' th $\epsilon$ residuals in \pm 0.05 was shown, the curves were split and the same log-transfo $n .{ }^{2}$ Logistic model with delay (section 3.2.1) was applied for fitting each of the tw: ) se stions of the observed curves, individually. Then, the fitted values from each $r_{i}, i e$ sections were aligned in a single

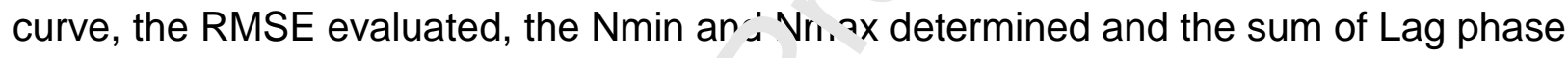
durations and $\mu$ max in the two phases was, yerformed.

The graphic evaluation of the fitting,$\epsilon_{-}$exemplified in Figures $3 B, 3 D$ and $3 F$. In addition, the much lower RMSE values in rabı 1 (RMSE (2)) indicated a good description of the observed data by applying the rroposed two-phase modelling approach. The improved fittings obtained with the, rok osed two-phases Logistic modelling approach was shown both when starter-lysate $\mathrm{v}$ as added (Figures 3B and D) and when grown without starterlysate (Figure 3F).

\subsection{Detailed evaluation of the effect of starter-lysate}

This evaluation focused on the growth phases of the 15 investigated NSLAB. To improve the robustness of the investigation, the graphic evaluation (Figures 2 and 3) was combined with the analysis of the parameter estimates in Table 1. Parameter estimates in Table 1 
are the sum of the parameter estimates obtained from the first (parameters in Table 2) and second phases of the proposed modelling approach. The parameter estimates related to the second phase of the modelling can be accessed by subtracting the values in Table 2 from the values in Table 1.

Most of the tested NSLAB showed an increased in growth. While 12 strains had increased $\mu$ max values, 10 strains had increased Nmax when starter-lysate was added. However, the degree of the effect varied between the species, with striins such as the cheese isolates $L b$. casei KU-LbC1 and Lb. rhamnosus KU-LbR1 (Figı res 2C, 20 and Table 1) and the Lb. coryniforms CCUG $30666^{\top}$ (Figure 2D anc $i^{\prime} h^{\prime} 21$ ) showing a high degree of the effect of the starter-lysate and the strains of $L k$ cur 'atus showing much less effect (Figures 2E, 2F and Table 1). In fact, decline o' li.e level of $L b$. curvatus cells initiated after about $20 \mathrm{~h}$ of incubation and the rate of $\mathrm{t}^{\mathrm{t}}$ in $\mathrm{a}_{\mathrm{c}}$.line was accelerated in presence of starter-lysate, especially after 110 . Porcella') et al. (2015) have also showed decay of $L b$. curvatus after extended periods of $i$ ' $i c$, hation. Despite the increase of only $3 \%$ in the $\mu$ max of $L b$. parabuchneri DSM $\because n 0 \zeta\urcorner^{\top}$, its Nmax was increased by $84 \%$, while for $L b$. coryniformis CCUG $30666^{\top}$ the increase of $\mathrm{Nmax}$ was only $72 \%$ regardless of the $100 \%$ increase in $\mu$ max (Table ), i his indicates that while for some species of NSLAB the effect of starter-lysate was imme diate and Nmax reached at an ealier stage, for other NSLAB this process occurs gradually due to a slower cell adaptation to the extra nutrients, supplied by the starter-lysate. The same phenomena seems to occur not only between different species but also within strains of the same species. In Table 1, the parameter estimates and the shape of the curves obtained for the two strains of $L b$. delbrueckii (Figures $2 \mathrm{G}$ and $2 \mathrm{H}$ ) and the two strains of $L b$. rhamnosus (Figures $2 \mathrm{~N}$ and $2 \mathrm{O}$ ) are different. When looking into the source of the obtained strains (Table 2), the combined 
increase in $\mu$ max and Nmax, and thus effectiveness of the starter-lysate in increasing the growth of the strains, seems to be highest for the cheese isolates $L b$ casei KU-LbC1 and Lb. rhamnosus KU-LbR1.

\subsection{Effect of inoculation level}

In Figure 4, the observed growth of Lb. casei KU-LbC1 (circular symbols) in absence (B) and in presence $(E)$ of starter-lysate is shown at inoculation . =vel of $7.0 \log _{10} \mathrm{CFU} \mathrm{mL}-1$. The parameter estimates obtained at the inoculum level of 5.0 og $_{10}$ CFU mL ${ }^{-1}$ (Tables 1 and 2) and when inoculating $L$ b. casei KU-LbC1 at the $t^{\prime \prime}{ }^{\prime \prime}$ of $7.0 \log _{10} \mathrm{CFU} \mathrm{mL} \mathrm{mL}^{-1}$ (Table 3) were compared. At the levels of $7.0 \log _{10}$ CFU $m^{-1}$ । o lag phase was shown and the magnitude of the effect of starter-lysate on $\mathrm{Nm}$ ax was much lower. Contrary to what is

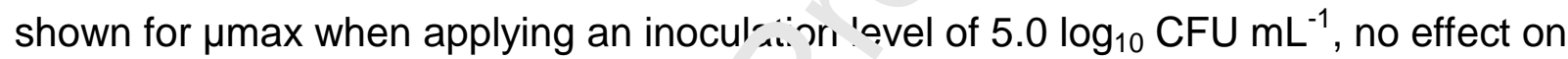
$\mu$ max was shown with an inoculation level $\_7.0 \log _{10} \mathrm{CFU} \mathrm{mL} \mathrm{m}^{-1}$. Removing the lag phase and applying parameters (Tables $1 \mathrm{tn}$ '? ?) from the lower inoculation level (black lines in Figures 4A and 4D) on observec' xrowth (circular symbols in Figures 4A and 4D) at 7.0 $\log _{10}$ CFU mL ${ }^{-1}$, it was shown i' ${ }^{\prime}$ ' the shape of the curve was very similar in the absence of starter-lysate (Figure 44), ixcept for the underestimation of the exponential phase, because it occurred fastar at an inoculation level of $7.0 \log _{10}$ CFU mL $\mathrm{m}^{-1}$. The same underestimation of the exponential phase was also shown in the presence of starter-lysate (black line in Figure 4D). Since a lower effect of starter-lysate was shown when applying a higher level of inoculation, the parameters obtained for $5.0 \log _{10} \mathrm{CFU} \mathrm{mL} \mathrm{m}^{-1}$ (Tables 1 and 2) had a different shape (black line in Figure 4D) than the observed values (circular symbols in Figure 4D), due to an overestimation of the maximum population density. 


\subsection{Effect of starter-lysate concentration and $\mathrm{NaCl}$}

When comparing with the same conditions, in the absence of $\mathrm{NaCl}$ (Figures 4B and 4C in Table 3), the effect of $\mathrm{NaCl}$ was clear, resulting in a drastic reduction of the $\mu$ max and Nmax, even when $10 \%$ of starter-lysate was present (grey and dashed black lines in Figure 5 and Table 3, respectively). When $33 \%$ starter-lysate was added to the medium with $\mathrm{NaCl}$ (solid black line in Figure 5 and Table 3), $\mu$ max was higher and about the same as in the scenario with $10 \%$ starter-lysate, but without $\mathrm{NaCl}$ "Fig 4-E and Fig 4-F in Table 3). However, even in presence of $33 \%$ starter-lysate wher. $\mathrm{Na}$; l was added, Nmax was about $40 \%$ lower than in the absence of $\mathrm{NaCl}$. The eff $\iota^{+} n^{\prime} \mathrm{NaCl}$ in promoting autolysis and consequently decay of optical density during ir ?ub tion of $L b$. casei was reported by Kang et al. (1998). The $\mathrm{NaCl}$ content also limit'; $u$ ine time of stationary phase, causing the

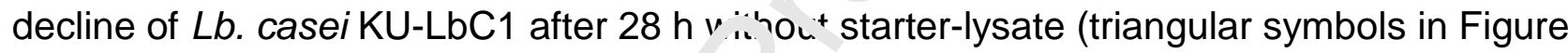
5), or after $45 \mathrm{~h}$ in the presence of $10 \%$ sta ter-lysate (squared symbols in Figure 5 ). The decline was not shown after $140 \mathrm{~h}("-1$,. $\mathrm{re}$ 4) without $\mathrm{NaCl}$, or before $60 \mathrm{~h}$ when $33 \%$ of starter-lysate was added (circulä: syrıbols in Figure 5), even in presence of $5.0 \% \mathrm{NaCl}$. This indicates that in the prese. $\urcorner \in$ of higher concentrations of starter-lysate an increased growth may be expected, evt $n$ under the limiting conditions as those found during cheese ripening. This is in agreerr ent with Czarán et al. (2018) who hypothesized that the availability and the level of nutrients released from SLAB are the main factors determining the rate of NSLAB growth during Cheddar cheese ripening.

\subsection{Composition of the starter-lysate}

$\mathrm{N}$-acetylglucosamine was present at the level of $2.47 \pm 0.01 \mathrm{~g} \mathrm{~L}^{-1}$ in the starter-lysate.

Changes in levels of this sugar were then monitored (Figure 6), before (bars in light grey) 
and after (bars in dark grey) $70 \mathrm{~h}$ incubation at $30^{\circ} \mathrm{C}$ of $L b$. rhamnosus KU-LbR1, in M17 broth (no lactose) without and with addition of $10 \%$ starter-lysate. It was shown that the level of $\mathrm{N}$-acetylglucosamine in the M17 broth without starter-lysate was about three times lower than in the M17 broth with starter-lysate (light grey bars in Figure 6), before incubation. While the level of $\mathrm{N}$-acetylglucosamine was nearly exhausted in the M17 broth without starter-lysate after $70 \mathrm{~h}$ incubation (dark grey bars in Figure 6), the M17 broth with the starter-lysate had more than half of the initial concentrat $\urcorner$ ר of $\mathrm{N}$-acetylglucosamine still available, which may explain the increased Nmax reached by $r$ lost of the tested NSLAB (Figure 2). This is in agreement with the findings of Ad $a_{1}$ herg et al. (2005), who simulated in a carbohydrate-restricted medium the effect of $N^{\prime}$ act 'ylglucosamine, that could potentially be released from lysed bacterial cel's. in the present study, the tested concentrations of 10 and $33 \%$ starter-lys $\mathrm{ui}^{\text {? }}$ a - 1 ded to the M17 broth 0.24 and $0.80 \mathrm{~g} \mathrm{~L}^{-1}$ $\mathrm{N}$-acetylglucosamine, respectively. These $\mathrm{K}$ yels are below the $\mathrm{N}$-acetylglucosamine levels of 2.5 and $10 \mathrm{~g} \mathrm{~L}^{-1}$ investigated pre 10 , sly on growth of NSLAB (Adamberg et al., 2005). No relevant differences in the ar: ino acids profile was shown between the M17 broth without (Figure 7A) or with $10 \%$ starter-lysate (Figure 7B) before incubation, or after $70 \mathrm{~h}$ incubation of $L b$. rhamno ius $<\mathrm{U}-\mathrm{LbR} 1$ at $30^{\circ} \mathrm{C}$ in M17 broth without (Figure $7 \mathrm{C}$ ). The increased level of the amr onium ion could be due to the decarboxylation of amino acids, however, considering the high level of ammonium ion, it is more probably that this ion is the product of the metabolism of $\mathrm{N}$-acetylglucosamine. Vesely et al. (2017) have reported that catabolism of $\mathrm{N}$-acetylglucosamine releases ammonia, which is similar to growth on amino acids. Further investigation would be necessary in order to clarify this point. Nevertheless, these results indicate that $\mathrm{N}$-acetylglucosamine content in the starter-lysate is the predominant factor in boosting the NSLAB growth. 


\subsection{Performance of the two-phases Logistic approach}

The suggested biphasic modelling approach was challenged on data from a second trial (Figure 4 and Table 3), developed with Lactobacillus casei KU-LbC1 applying the same conditions as in the first trial, excepting for a higher inoculation level $\left(7.0 \log _{10} \mathrm{CFU} \mathrm{mL} \mathrm{m}^{-1}\right)$. The performance of the simulations obtained with the suggested approach applying the parameters of the fittings, shown in Tables 1 (sum of paramitars from phases 1 and 2) and 2 (only parameters from phase 1) was evaluated throu a $\mathrm{t} t \mathrm{te}$ acceptable simulation zone (ASZ) concept (Oscar, 2005). With the corrected bc s. ine (as described in section 2.4), most of the simulated values (93.0\%) were $\mathbf{u}^{\prime}$ - hin the ASZ (zone between dotted lines in Figure 4) when the availability of nutrie' « was low (Figure 4A). However, it is important to take into account that when $\ldots$ N. . nin of the observed data was $7.0 \log _{10} \mathrm{cfu}$ $\mathrm{mL}^{-1}$ the Nmax was reached at an earlier sı $\mathrm{nge}$ and therefore the data points outside ASZ was underestimated during the expr,n, ntral phase, which makes the simulation of a faildangerous nature. As pointed ol by Oscar (2011), this fail-dangerous feature needs to be taken into consideration. The s:mulation performed on the same dataset but with addition of starter-lysate gave an ?vel poorer description of the observed data (Figure 4D) with only $43.0 \%$ of the simulat d data points inside the ASZ. Nevertheless, the suggested twophases approach gives a reasonable description of the observed data, according to the low RMSE values (Table 3) and the graphic evaluation both at reduced (Figures 4B and 4C) and at increased (Figures 4E and 4F) availability of nutrients, when applied for fitting purpose. The good performance of the model (Figures 4B and 4E) was achieved when using the split point between phase 1 and phase 2 (last data point in the fitting of the first phase of the approach, as shown in Table 2). This is particular relevant, considering that 
the decision making for the split point is very time consuming, requiring fitting of the observed data with the traditional one-phase Logistic model, followed by graphic evaluation and defining of the persistent deviation of the residuals $( \pm 0.05)$. As shown in (Figures 4C and 4F) and according to the RMSE values (Table 3) the improvement of the fittings is not always achieved (Figure 4F) or significant. Therefore, the split point indicated in Table 2 seems to be independent of the inoculation level, and may be usefull when applying the two-phases Logistic approach on the conditions +ested in this study. By fitting the observed data in a third trial (Figure 5), it was shown th at $b$ ssides the different initial density of $L A B$, the good fitting with the proposed appr Ja ${ }^{-h}$ was also achieved when an extra stress factor was included $(5.0 \% \mathrm{NaCl})$. Furt' ern ore, the goodness of fit was shown to be independent of the level of nutrients as ir u a case where the level of nutrients was

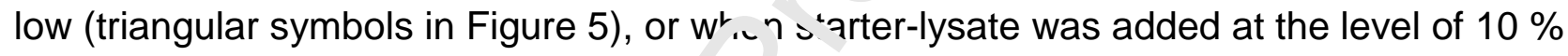
(square in Figure 5) or $33 \%$ (circular symo 's in Figure 5), confirmed by graphic evaluation (lines in Figure 5) and th $, 1, v$ values of RMSE (Table 3). 


\section{Conclusions}

The suggested two-phases Logistic approach was successfully applied and allowed the evaluation of the effect of starter culture lysate on NSLAB growth. The starter-lysate boosted the growth of 13 of the tested NSLAB. This boosting effect was shown to be species as well as strain dependent. The effect of the starter-lysate was more prominent when NSLAB were inoculated at low levels. The starter-lysate was able to boost growth of $\mathrm{NSLAB}$ even when $\mathrm{NaCl}$ was present at high concentration. ${ }^{\mathrm{D}} \mathrm{y}$ increasing the level of the starter-lysate the boosting effect in NSLAB growth was ma 'imı :ed and it nearly annulled the stress effect of salt. Furthermore, the effect of the tinto. -lysate was greatest on the growth of $L b$. casei KU-LbC1 and $L b$. rhamnosus $K J-L, R 1$, isolated from vintage Cheddar cheese. The presence of $\mathrm{N}$-acetylglur,u: amine in the starter-lysate and its decline during NSLAB development indicates thr: : :his may be the predominant nutrient, responsible for the boosting effect on NSLr.9 growth. In conclusion, the developed modelling approach enabled investi $ر a$..ng of the dynamics of starter-NSLAB interactions, which may allow the scientific cc: nmunity to generate new insights about the mechanisms involved in these bacterial inte, $?$ cion during cheese ripening, and support the industry to improve quality in cheese prc duction. 


\section{Acknowledgements}

This research was supported by the Innovation Fund Denmark and Arla Foods amba

[grant number 064-2014-5]. The authors appreciate the technical support of Bashir Aideh, Mónica Martínez, Niels Arneborg (Department of Food Science, University of

Copenhagen), Rodrigo Bibiloni (Arla Foods amba), Tina Beck Hansen and Maarten Nauta (National Food Institute, Technical University of Denmark). 


\section{Reference}

Adamberg K., Antonsson, M., Vogensen, F. K., Nielsen, E. W., Kask, S., Møller, P. L., Ardö, Y., 2005. Fermentation of carbohydrates from cheese sources by non-starter lactic acid bacteria isolated from semi-hard Danish cheese. Int. Dairy J. 15, 873-882.

Alessandria, V., Ferrocino, I., de Filippis, F., Fontana, M., Rantsiou, K., Ercolini, D.

Cocolin, L., 2016. Microbiota of an Italian Grana-like cheese during manufacture and ripening, unravelled by $16 \mathrm{~S}$ rRNA-based approaches. Anbı. Fnviron. Microbiol. 82, 3988-3995.

Broadbent, J. R., Brighton, C., McMahon, D. J., Far'.y ? iJ. Y., Johnson, M. E., Steele, J. L., 2013. Microbiology of Cheddar cheese mac'e wi'h different fat contents using a Lactococcus lactis single-strain starter. I Lain y Sci. 96, 4212-4222.

Calasso, M., Minervini, F., de Filippis, F., L ${ }^{r}$ colini, D., de Angelis, M., Gobbetti, M., 2020. Attenuated Lactococcus lactis a' '' su.face bacteria as tools for conditioning the microbiota and driving the ripenı y of semisoft Caciotta cheese. Appl. Environ. Microbiol. 86, 1-18.

Czarán, T., Rattray, F P. Meller, C. O. de A., Christensen, B. B., (2018). Modelling the influence of metabo':tr, diffusion on non-starter lactic acid bacteria growth in ripening Cheddar cheese. Int. Dairy J. 80, 35-45.

Dalgaard, P., 2009. Modelling of microbial growth. Bull. Int. Dairy Fed. 433, 45-57. de Pasquale, I., di Cagno, R., Buchin, S., de Angelis, M., Gobbetti, M., 2019. Use of autochthonous mesophilic lactic acid bacteria as starter cultures for making Pecorino Crotonese cheese: effect on compositional, microbiological and biochemical attributes. Food Res. Int. 116, 1344-1356. 
Gantzias, C., Lappa, I. K., Aerts, M., Georgalaki, M., Manolopoulou, E., Papadimitriou, K., de Brandt, E., Tsakalidou, E., Vandamme, P., 2020. MALDI-TOF MS profiling of nonstarter lactic acid bacteria from artisanal cheeses of the Greek island of Naxos. Int. J. Food Microbiol. 323, 1-6.

Gobbetti, M., de Angelis, M., di Cagno, R., Mancini, L., Fox, P. F., 2015. Pros and cons for using non-starter lactic acid bacteria (NSLAB) as secondary/adjunct starters for cheese ripening. Trends Food Sci. Technol. 45, 167-178.

Guerra, N. P., Fajardo, P., Fuciños, C., Amado, I. R., Alrıюn, 亡., Torrado, A., Pastrana, L., 2010. Modelling the biphasic growth and product tc "mation by Enterococcus faecium CECT 410 in realkalized fed-batch fermentations $: 1$ whey. J. Biomed. Biotechnol. 2010, 1-16.

Kang, O. J., Véziz, L.-P., Laberge, S.; Sı^^^rd, R. E., 1998. Some factors influencing the autolysis of Lactobacillus bulgarirus and Lactobacillus casei. J. Dairy Sci. 81, 639-646.

Lloyd, L., 2008. HPLC analysis n suvars and glycoproteins in biological systems. Agilent Technologies, Inc., Santá Slà:a, USA. SI-01410.

Meyer., P., 1994. Bi-lcris ic o owth. Technol. Forecasting Social Change 47, 89-102. Montel, M.-C., Buchin, S., Mallet, A., Delbes-Paus, C., Vuitton, D. A., Desmasures, N., Berthier, F., 2014. Traditional cheeses: rich and diverse microbiota with associated benefits. Int. J. Food Microbiol. 177, 136-154.

Mugampoza, D., Gkatzionis, K., Swift, B. M. C., Rees, C. E. D., Dodd, C. E. R., 2020. Diversity of Lactobacillus species of Stilton cheese relates to site of isolation. Front. Microbiol. 11, 1-12. 
Møller, C. O. de A., Ilg. Y., Aabo, S., Christensen, B. B., Dalgaard, P., Hansen, T. B., 2013. Effect of natural microbiota on growth of Salmonella spp. in fresh pork - a predictive microbiology approach. Food Microbiol. 34, 284-295.

Møller, C. O. de A., Sant'Ana, A. S., Hansen, S. K. H., Nauta, M. J., Silva, L. P., Alvarenga, V. O., Maffei, D., Silva, F. F. P., Lopes, J. T., Franco, B. D. G. M., Aabo, S., Hansen, T. B., 2016. Evaluation of a cross contamination model describing transfer of Salmonella spp. and Listeria monocytogenes during grinu.ng of pork and beef. Int. J. Food Microbiol. 226, 42-52.

Møller, C. O. de A., Ücok, E. F., Rattray, F. P., 2020. Fistamine forming behaviour of bacterial isolates from aged cheese. Food Res 1 . 128, 1-10.

Ortakci, F., Broadbent, J. R., Oberg, C. J., M :Micu'ion, D. J., 2015. Late blowing of Cheddar cheese induced by accelerated ripe , $^{-} y$ y and ribose and galactose supplementation in presence of a novel obligatory hete, רfermentative nonstarter Lactobacillus wasatchensis. J. Dairy Sci. 9؟, 74ūJ-7472.

Oscar, T. P., 2005. Validation of ı.g time and growth rate models for Salmonella Typhimurium: accept ^DIc prediction zone method. J. Food Sci. 70, M129-M137.

Oscar, T. P., 2011. Devs'spment and validation of a predictive microbiology model for survival and growth of Salmonella on chicken stored at 4 to $12^{\circ} \mathrm{C}$. J. Food Prot. 74 , 279-284.

Pangallo, D., Kraková L., Puškárová, A., Šoltys, K., Bučková, M., Koreňová, J., Budiš, J., Kuchta, T., 2019. Transcription activity of lactic acid bacterial proteolysis-related genes during cheese maturation. Food Microbiol. 82, 416-425. 
Peterson, S. D., Marshall, R. T., 1990. Nonstarter Lactobacilli in Cheddar cheese, a review. J. Dairy Sci. 73, 1395-1410.

Porcellato, D., Johnson, M. E., Houck, K., Skeie, S. B., Mills, D.A., Kalanetra, K. M., 2015. Potential of Lactobacillus curvatus LFC1 to produce slits in Cheddar cheese. Food Microbiol. 49, 65-73.

Saidi, V., Sheikh-Zeinoddin, M., Kobarfard, F., Soleimanian-Zad, S., 2020. Bioactive characteristics of a semi-hard non-starter culture cheese minde from raw or pasteurized sheep's milk. 3 Biotech. 10, 1-8.

Settanni, L., Moschetti, G., 2010. Non-starter lactic «u: ‘ ivacteria used to improve cheese quality and provide health benefits. Food Micrc oioı. 27, 691-697.

Thomas, T., 1987. Cannibalism among bontt.ia tound in cheese. N. Z. J. Dairy Sci. Technol. 22, 215-219.

Velugoti, P. R., Bohra, L. K., Juneja I. '^., Huang, L., Wesseling, A. L., Subbiah, J., Thippareddi, H., 2011. Dynaı. 'ic model for prediction growth of Salmonella spp. in ground sterile pork. Food Ni:-robiol. 205, 53-72.

Vesely, E. M., Williams, F. R., Konopka, J. B., Lorenz, M. C., 2017. N-Acetylglucosamine metabolism promotes survival of Candida albicans in the phagosome. mSphere 2, e00357-17.

Wallace, J. M., Fox, P. F., 1997. Effect of adding free amino acids to Cheddar cheese curd on proteolysis, flavour and texture development. Int. Dairy J. 7, 157-167.

Wilson, K. L., Honsey, A. E., Moe, B., Venturelli, P., 2017. Growing the biphasic framework: techniques and recommendations for fitting emerging growth models. Methods Ecol. Evol. 9, 822-833. 
Wouters, J. T. M., Ayad, E. H. E., Hugenholtz, J., Smit, G., 2002. Microbes from raw milk for fermented dairy products. Int. Dairy J. 12, 91-109. 


\section{Tables}

Table 1. Sum of growth parameters ${ }^{\square, \beta}$ obtained modelling the effect of starter culture lysate on incubation ${ }^{\star}$ of lactic acid bacteria (LAB)

\begin{tabular}{|c|c|c|c|c|c|c|c|c|c|c|c|c|}
\hline \multirow[t]{2}{*}{ LAB } & \multicolumn{6}{|c|}{ Without starter-lysate ${ }^{\alpha}$} & \multicolumn{6}{|c|}{ With starter-lysate ${ }^{\alpha}$} \\
\hline & $\begin{array}{l}\text { Lag phase }{ }^{\beta} \\
\text { (h) }\end{array}$ & $\underset{\left(h^{-1}\right)}{\mu \max ^{\beta}}$ & $\underset{\left(O D_{600 \mathrm{~nm}}\right)}{\mathrm{Nmin}}$ & $\begin{array}{c}\text { Nmax } \\
\left(O_{600 \mathrm{~nm}}\right)\end{array}$ & $\begin{array}{c}R M S E \\
(1)\end{array}$ & $\begin{array}{c}R M S E \\
\text { (2) }\end{array}$ & $\begin{array}{l}\text { Lag phase }{ }^{\beta} \\
\text { (h) }\end{array}$ & $\underset{\left(h^{-1}\right)}{\mu \max ^{\beta}}$ & $\begin{array}{c}\text { Nmin } \\
\left(O_{600 \mathrm{~nm}}\right)\end{array}$ & $\begin{array}{c}\text { Nmax } \\
\left(\mathrm{OD}_{600 \mathrm{~nm}}\right)\end{array}$ & $\begin{array}{c}R M S E \\
(1)\end{array}$ & $\begin{array}{c}R M S E \\
(2)\end{array}$ \\
\hline Lc. lactis subsp. cremoris (starter) & 4.682 & 0.694 & 0.0007 & 0.1246 & 0.044 & 0.014 & $25.11 i^{\nabla}$ & 0.709 & 0.0013 & 0.1235 & 0.051 & 0.027 \\
\hline Lc. lactis subsp. lactis (starter) & 2.101 & 0.849 & 0.0014 & 0.1272 & 0.052 & 0.018 & $0.98^{*}$ & 0.863 & 0.0005 & 0.1418 & 0.099 & 0.013 \\
\hline Lb. brevis CCUG 30670' & 1.953 & 0.412 & 0.0007 & 0.1524 & 0.032 & $0.01^{n}$ & $2.405^{\nabla}$ & $0.508^{*}$ & 0.0013 & $0.3105^{*}$ & 0.053 & 0.014 \\
\hline Lb. casei subsp. lactis DSM $20011^{\prime}$ & 0.000 & 0.243 & 0.0053 & 0.1549 & 0.032 & nOl & $1.218^{\nabla}$ & $0.324^{*}$ & 0.0063 & $0.2163^{*}$ & 0.060 & 0.006 \\
\hline Lb. casei (KU-LbC1) & 3.887 & 0.399 & 0.0020 & 0.2108 & 0.111 & $0.0 \cdot 4$ & 3.848 & $0.590^{*}$ & 0.0005 & $0.5659^{*}$ & 0.047 & 0.020 \\
\hline Lb. coryniformis CCUG $30666^{\prime}$ & 2.129 & 0.530 & 0.0007 & 0.1650 & 0.297 & $\cap \cap \_6$ & $5.516^{\nabla}$ & $1.062^{*}$ & 0.0007 & $0.2842^{*}$ & 0.030 & 0.023 \\
\hline Lb. curvatus CCUG 30669' & 3.690 & 0.899 & 0.0020 & 0.0230 & $1.2 \%:$ & 0.171 & $0.938^{*}$ & $0.717^{\nabla}$ & 0.0001 & 0.0811 & 0.365 & 0.022 \\
\hline Lb. curvatus DSM $20019^{\prime}$ & 2.709 & 0.875 & 0.0010 & $0.0 ?=$ & $c \div 64$ & 0.025 & $1.536^{*}$ & $0.590^{\nabla}$ & 0.0013 & 0.0832 & 0.446 & 0.027 \\
\hline Lb. delbrueckii subsp. bulgaricus DSM $20081^{\prime}$ & 4.000 & 0.449 & 0.0005 & 0.589 & 0.037 & 0.038 & $3.757^{*}$ & $0.711^{*}$ & 0.0005 & $0.6644^{*}$ & 0.050 & 0.025 \\
\hline Lb. delbrueckii subsp. delbrueckii CCUG 34222 ' & 7.311 & 0.599 & 0.0003 & $0.1,, 4$ & 0.059 & 0.039 & $3.930^{*}$ & $0.690^{*}$ & 0.0005 & $0.3981^{*}$ & 0.048 & 0.020 \\
\hline Lb. fermentum DSM $20052^{\prime}$ & 13.890 & 0.215 & 0.0010 & $0.03 i$ & 0.023 & 0.018 & $12.308^{*}$ & $0.265^{*}$ & 0.0010 & $0.1370^{*}$ & 0.027 & 0.018 \\
\hline Lb. helveticus CCUG 30139' & 2.181 & 0.503 & $0.00 r^{\circ}$ & ר.2882 & 0.082 & 0.022 & $3.292^{\nabla}$ & $0.706^{*}$ & 0.0005 & 0.3271 & 0.031 & 0.018 \\
\hline Lb. parabuchneri DSM $20057^{\prime}$ & 2.731 & 0.404 & 0.710 & 0.0907 & 0.059 & 0.029 & $2.437^{*}$ & 0.415 & 0.0017 & $0.1665^{*}$ & 0.044 & 0.013 \\
\hline Lb. paracasei NCFB $151^{\prime}$ & 2.327 & 0.351 & $1.06>8$ & 0.0495 & 0.028 & 0.026 & $3.681^{\nabla}$ & $0.386^{*}$ & 0.0012 & 0.0934 & 0.037 & 0.025 \\
\hline Lb. plantarum subsp. plantarum ATCC $14917^{\prime}$ & 1.811 & 0.455 & 0.7007 & 0.2846 & 0.084 & 0.034 & $4.667^{\nabla}$ & $0.743^{*}$ & 0.0007 & 0.3191 & 0.028 & 0.018 \\
\hline Lb. rhamnosus DSM $20021^{\prime}$ & 3.582 & C 330 & 0.0013 & 0.3252 & 0.087 & 0.019 & 3.483 & $0.484^{*}$ & 0.0012 & $0.4840^{*}$ & 0.104 & 0.018 \\
\hline Lb. rhamnosus (KU-LbR1) & 2.610 & $? 14$ & 0.0019 & 0.2341 & 0.128 & 0.028 & $3.298^{\nabla}$ & $0.518^{*}$ & 0.0007 & $0.5629^{*}$ & 0.190 & 0.019 \\
\hline
\end{tabular}

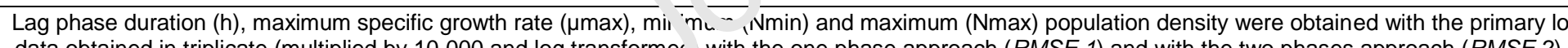

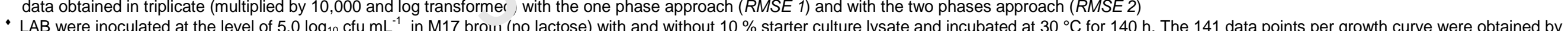
- LAB were inoculated at the level of $5.0 \log _{10} \mathrm{cfu}_{\mathrm{mL}}^{-1}$
measuring the optical density every hour after shaking.

$\alpha$ Values of lag phase, $\mu \max , \mathrm{Nmin}$ and Nmax were fitted using the modelling approach with lower values of RMSE (highlighted in bold).

$\beta$ Lag phase duration and $\mu$ max obtained by applying the two-phases approach are the sum of values obtained in each phase.

Differences in the parameter estimates identified as significant at the level of $0.05 \%$ with the Student's paired $t$-test were classified as: ${ }^{(*)}$ Positive effect of starter-lysate on growth of LAB; or

v) Negative effect of starter-lysate on growth of $L A B$. 


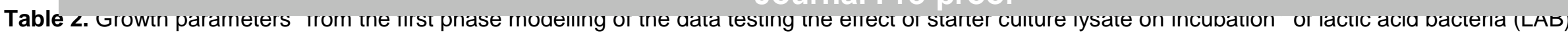

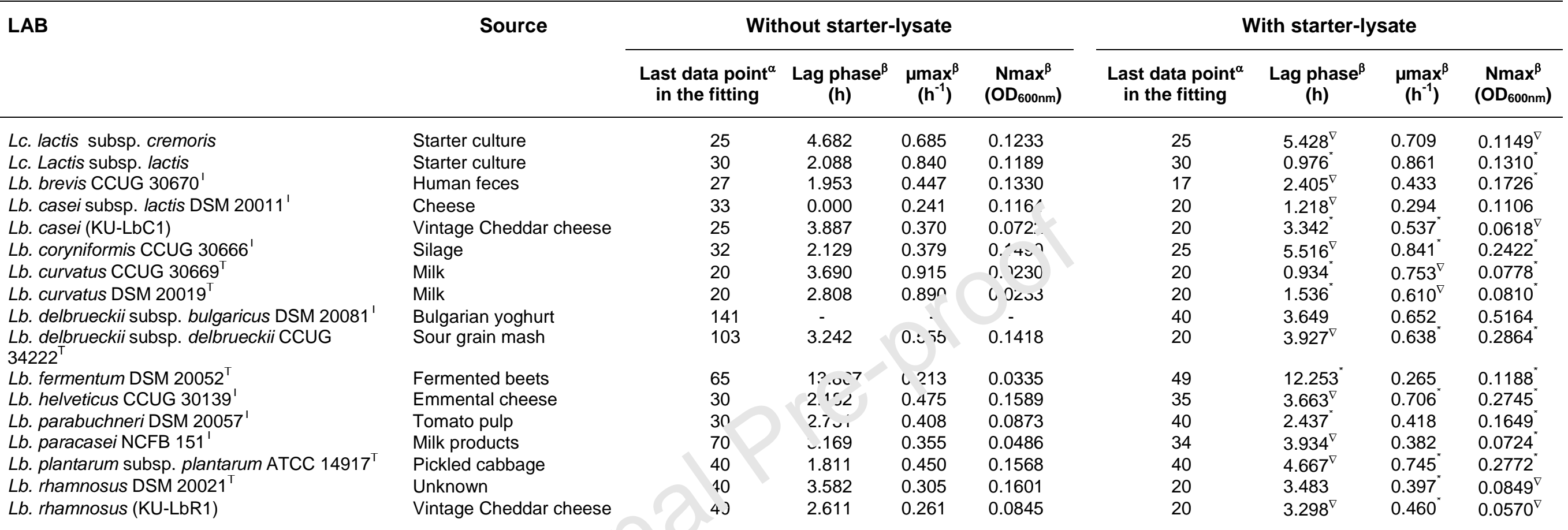

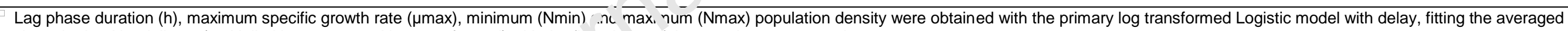
data obtained in triplicate (multiplied by 10,000 and log transformed) with the fir. ' phi 'e of the two phases approach.

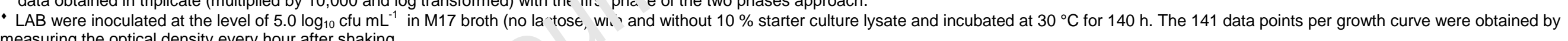
measuring the optical density every hour after shaking.

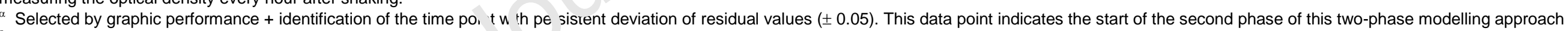
${ }^{\beta}$ Lag phase duration, $\mu$ max and Nmax values for the second phas, ol hic ,wo-phases approach can be obtained by abstracting the values in this table from the total values shown in Table 1.

Differences in the parameter estimates identified as significant at the evel of $0.05 \%$ with the Student's paired $t$-test were classified as: ${ }^{* *}$ Positive effect of starter-lysate on growth of LAB; or

(D) Negative effect of starter-lysate on growth of $L A B$. 


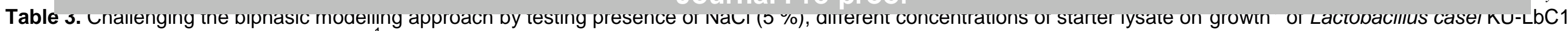
inoculated at high level $\left(7.0 \log _{10} \mathrm{cfu} \mathrm{\textrm {mL } ^ { - 1 } )}\right.$

\begin{tabular}{|c|c|c|c|c|c|c|c|c|c|c|c|c|c|}
\hline \multirow[t]{2}{*}{ Fitting $^{*}$ code } & \multirow{2}{*}{$\begin{array}{c}\mathrm{NaCl} \\
\text { added } \\
(\%)\end{array}$} & \multirow{2}{*}{$\begin{array}{l}\text { Starter- } \\
\text { Iysate } \\
\text { level } \\
(\%)\end{array}$} & \multirow{2}{*}{$\begin{array}{c}\text { Time of } \\
\text { incubation } \\
\text { (h) }\end{array}$} & \multicolumn{5}{|c|}{ Phase 1} & \multicolumn{4}{|c|}{ Phase 2} & \multirow[t]{2}{*}{ RMSE $^{\beta}$} \\
\hline & & & & $\begin{array}{l}\text { Last data } \\
\text { point in the } \\
\text { fitting }\end{array}$ & $\begin{array}{c}\text { Lag } \\
\text { phase (h) }\end{array}$ & $\underset{\left(h^{-1}\right)}{\mu \max }$ & $\begin{array}{c}\text { Nmin } \\
\left(O D_{600 \mathrm{~nm}}\right)\end{array}$ & $\begin{array}{c}\text { Nmax } \\
\left(O D_{600 \mathrm{~nm}}\right)\end{array}$ & $\begin{array}{c}\text { First data } \\
\text { point in the } \\
\text { fitting }\end{array}$ & $\begin{array}{l}\text { Lag phase } \\
\text { (h) }\end{array}$ & $\underset{\left(h^{-1}\right)}{\mu \max }$ & $\underset{\left(O D_{600 \mathrm{~nm}}\right)}{N \max }$ & \\
\hline Figure 4B & - & - & 140 & $25^{\nabla}$ & - & $0.390^{a}$ & 0.0124 & $0.1453^{a}$ & $25^{\nabla}$ & 0.507 & $0.032^{a}$ & $0.3786^{\mathrm{a}, \mathrm{c}}$ & $0.0317^{a}$ \\
\hline Figure 4C & - & - & 140 & $16^{\alpha}$ & - & $0.439^{a}$ & 0.0116 & $0.1292^{b}$ & $16^{\alpha}$ & 0.665 & $0.029^{a}$ & $0.3878^{\mathrm{a}, \mathrm{c}}$ & $0.0303^{a}$ \\
\hline Figure 4E & - & 10 & 140 & $20^{\nabla}$ & 0.602 & $0.342^{b}$ & 0.0173 & $0.1497^{a}$ & $20^{\nabla}$ & - & $0.064^{b}$ & $0.6330^{\mathrm{b}}$ & $0.0241^{b}$ \\
\hline Figure 4F & - & 10 & 140 & $15^{\alpha}$ & - & $0.352^{\mathrm{b}}$ & 0.0149 & $0.1372^{c}$ & $15^{\alpha}$ & - & $0.060^{\mathrm{b}}$ & $0.6375^{\mathrm{b}}$ & $0.0259^{b}$ \\
\hline $\begin{array}{l}\text { Figure } 5 \\
\text { (grey line) }\end{array}$ & 5 & - & 70 & $25^{\alpha}$ & 0.171 & $0.198^{\mathrm{C}}$ & 0.0393 & $0.1671^{d}$ & $25^{\alpha}$ & 0.016 & $-0.044^{c}$ & $0.2305^{d}$ & $0.0165^{c}$ \\
\hline $\begin{array}{l}\text { Figure } 5 \\
\text { (dashed black } \\
\text { line) }\end{array}$ & 5 & 10 & 70 & $50^{\alpha}$ & - & $0.190^{C}$ & 0.0297 & $J .1 .5 i^{e}$ & $50^{\alpha}$ & 0.157 & $-0.081^{d}$ & $0.3401^{c}$ & $0.0308^{a}$ \\
\hline Figure 5 & 5 & 33 & 70 & $10^{\alpha}$ & - & $0.368^{\mathrm{b}}$ & C J2: 0 & $0.1223^{\dagger}$ & $10^{\alpha}$ & 0.371 & $0.084^{e}$ & $0.3950^{a}$ & $0.0314^{a}$ \\
\hline (solid black line) & & & & & & & & & & & & & \\
\hline
\end{tabular}

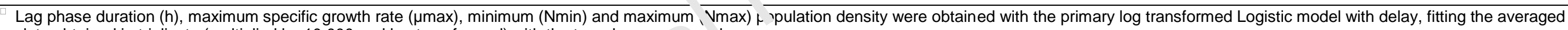
data obtained in triplicate (multiplied by 10,000 and log transformed) with the two phases - $\mathrm{Nr}$ oa, $\mathrm{h}$

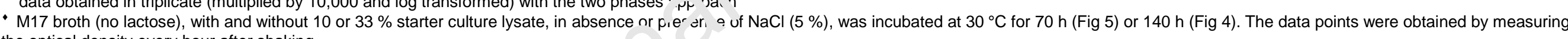
the optical density every hour after shaking.

* Same codes used in Figure 4 (B to F) and Figure 5 (lines), where the related gr n vth urve; are shown.

The same time point applied when modelling the dataset inoculated at the le، 91 ' ' $5.0 .0 \mathrm{gg}_{10} \mathrm{cfu} \mathrm{mL}^{-1}$ and shown in Table 2.

${ }^{\alpha}$ Selected by graphic performance + residual values indicating difference $l_{c}$ ' ger ' 'alı \pm 0.05 continuously in the remaining time points.

$\beta$ RMSE values were obtained with all data points of the entire $C^{\prime}$ rve, $x_{C}, d_{i} r{ }^{+}$'ie first data point in the fitting of the second phase of the modelling approach, to avoid repetition of this data point.

$a, b, c$ Within a same column, values of parameter estimates and RI SE with ame letters indicates that the differences are not significant at the level of $0.05 \%$, according to the Student's paired $t$-test. 
Figure 1 Growth of SLAB in presence (closed symbols in black) and absence (open symbols in grey) of $10 \%$ starter lysate, added to the M17 broth (without lactose). Starter culture representatives, Lactococcus lactis subsp. cremoris $(\mathrm{A})$ and Lactococcus lactis subsp. lactis (B), were individually inoculated at the level of about $5.0 \log _{10} \mathrm{CFU} \mathrm{mL} \mathrm{m}^{-1}$. Optical density at $600 \mathrm{~nm}$ was measured for $140 \mathrm{~h}$ at $30^{\circ} \mathrm{C}$

Figure 2 Growth of NSLAB in presence (closed symbols in black) and absence (open symbols in grey) of $10 \%$ starter culture lysate, added to the M17 broth (without lactose). Lb. brevis CCUG $30670^{\top}(\mathrm{A})$, Lb. casei subsp. lactis DSM $20011^{\top}(\mathrm{B})$, Lb. casei $\mathrm{KU}-\mathrm{LbC1}(\mathrm{C})$, Lb. coryniformis CCUG $30666^{\top}$ (D), Lb. curvatus DSM $20019^{\top}(\mathrm{E})$, Lb. curvatus CCUG $30669^{\top}(\mathrm{F})$, Lb. delbrueckii subsp. bulgaricus DSM $20081^{\top}(\mathrm{G})$, Lb. delbrueckii subsp. delbrueckii CCUG $34222^{\top}(\mathrm{H}), L b$. fermentum DSM $20052^{\top}(\mathrm{I})$, Lb. helveticus CCUG $30139^{\top}(\mathrm{J})$, Lb. parabuchneri DSM $20057^{\top}(\mathrm{K})$, Lb. paracasei NCFB $151^{\top}(\mathrm{L})$, Lb. plantarum subsp. plantarum ATCC $14917^{\top}(\mathrm{M})$, Lb. rhamnosus DSM $20021^{\top}(\mathrm{N})$ and $L b$. rhamnosus KU-LbR1 (O). Each strain was individually inoculated at the level of about $5.0 \log _{10} \mathrm{CFU} \mathrm{mL} \mathrm{m}^{-1}$. Optical density at $600 \mathrm{~nm}$ mec r. ured for $140 \mathrm{~h}$ at $30{ }^{\circ} \mathrm{C}$ was multiplied by 10,000 before log-transformed.

Figure 3 Observed (symbols in grey) and fitted (line in blacl.) y: 0 wth of NSLAB in M17 broth (no lactose) with $10 \%(A$ to $D)$ or without $(E$ and $F)$ starter lys tt ${ }^{\circ}+30^{\circ} \mathrm{C}$ for $144 \mathrm{~h}\left(O_{600 \mathrm{~nm}}\right)$. The primary log transformed Logistic model with delay was annind in a single phase (A, C and E) or using the proposed two-phases approach (B, D and F), Op ical Density values were multiplied 10,000 times and $\log _{10}$ transformed, in order to perforr. 1 . ndelling. Lactobacillus rhamnosus DSM $20021 \mathrm{~T}(\bullet, \mathrm{A}$ and B), Lactobacillus rhamnosus KL'-L JR1 ( $\mathbf{\Delta}, \mathrm{C}$ and D) and Lactobacillus casei

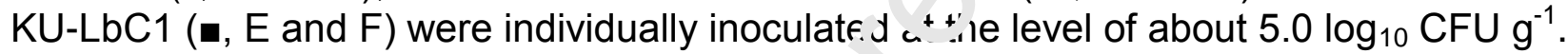

Figure 4 Observed (symbols in grey), simuı ${ }^{+} f d$ with parameters in Tables 1 and 2 (black line in $A$ and D), and fitted (black line in B, C, E and F) y. owth of Lactobacillus casei KU-LbC1, inoculated at the level of $7.0 \log _{10} \mathrm{cfu} \mathrm{mL}^{-1}$ in $\mathrm{M} 17 \mathrm{bro}^{\text {h }}$ (no lactose) without (A, B and C) and with (D, E and F) starter lysate, during $140 \mathrm{~h}$ at $30^{\circ} \mathrm{C}$. Tr.t acceptable simulation zone (ASZ) concept was applied considering OD $\pm 0.14 \log _{10} C=$ ( limited by the dotted grey lines in $A$ and $\left.D\right)$. Simulations performed testing abseri: $(A)$ and presence (D) of starter lysate generated RMSE values of 0.264 and 0.376 , respech aly. Fittings were performed applying the same end point in phase 1 as indicated in Table 2 ( $B$ c nd $E$ ) or corrected $(C$ and $F$ ) according graphic evaluation and residuals with difference below $+\imath$ 'J5.

Figure 5 Observed (symbols; and fitted (lines) growth of Lactobacillus casei KU-LbC1 (inoculated at $7.0 \log _{10} \mathrm{CFU} \mathrm{mL} \mathrm{m}^{-1}$ ) in ab- nce (triangular symbols and continuous grey line) or in presence of $10 \%$ (squared symbols and dashed black line) or $33 \%$ (circular symbols and continuous black line) starter culture lysate, added to the M17 broth (without lactose). $\mathrm{NaCl}$ was added to the level of $5.0 \%$ to simulate conditions found in Cheddar cheese. Averaged of triplicate values of optical density obtained at $600 \mathrm{~nm}$ was measured for $70 \mathrm{~h}$ at $30^{\circ} \mathrm{C}$. The averaged data points were multiplied by 10,000 before log transformed, and then modelled with the two-phases approach.

Figure 6 Concentration of $\mathrm{N}$-acetylglucosamine $\left(\mathrm{g} \mathrm{L}^{-1}\right)$ in $\mathrm{M} 17$ broth without or with $10 \%$ lysate. Samples inoculated with Lactobacillus rhamnosus KU-LbR1 were analysed before (light grey bars) and after (dark grey bars) $71 \mathrm{~h}$ at $30^{\circ} \mathrm{C}$ with enzymatic assay. The results are shown as averaged triplicates and error bars are shown in black.

Figure 7 Amino acids profile (Absorbance Unit at $280 \mathrm{~nm}$ ) before incubation of $\mathrm{M} 17$ broth without (A) and with (B) $10 \%$ starter lysate, or after $70 \mathrm{~h}$ incubation of $\mathrm{Lb}$. rhamnosus $\mathrm{KU}-\mathrm{LbR} 1$ at $30^{\circ} \mathrm{C}$ in M17 broth without (C) or with $10 \%$ starter lysate (D) 


\section{Highıignis}

- An enzymatic protocol to digest starter culture was developed and applied

- The effect of the obtained lysate was tested on growth of 15 non-starter and 2 starter lactic acid bacteria (SLAB)

- Lack-of-fit by applying log-transformed Logistic model was shown due to biphasic growth

- A two-phases Logistic modelling approach was proposed and successfully applied

- $\mathrm{N}$-glucosamine from SLAB cell wall seem to be the responsible for the increased growth of most tested non-starter LAB

- The effect of starter lysate was shown to be species and strain dependent 
A

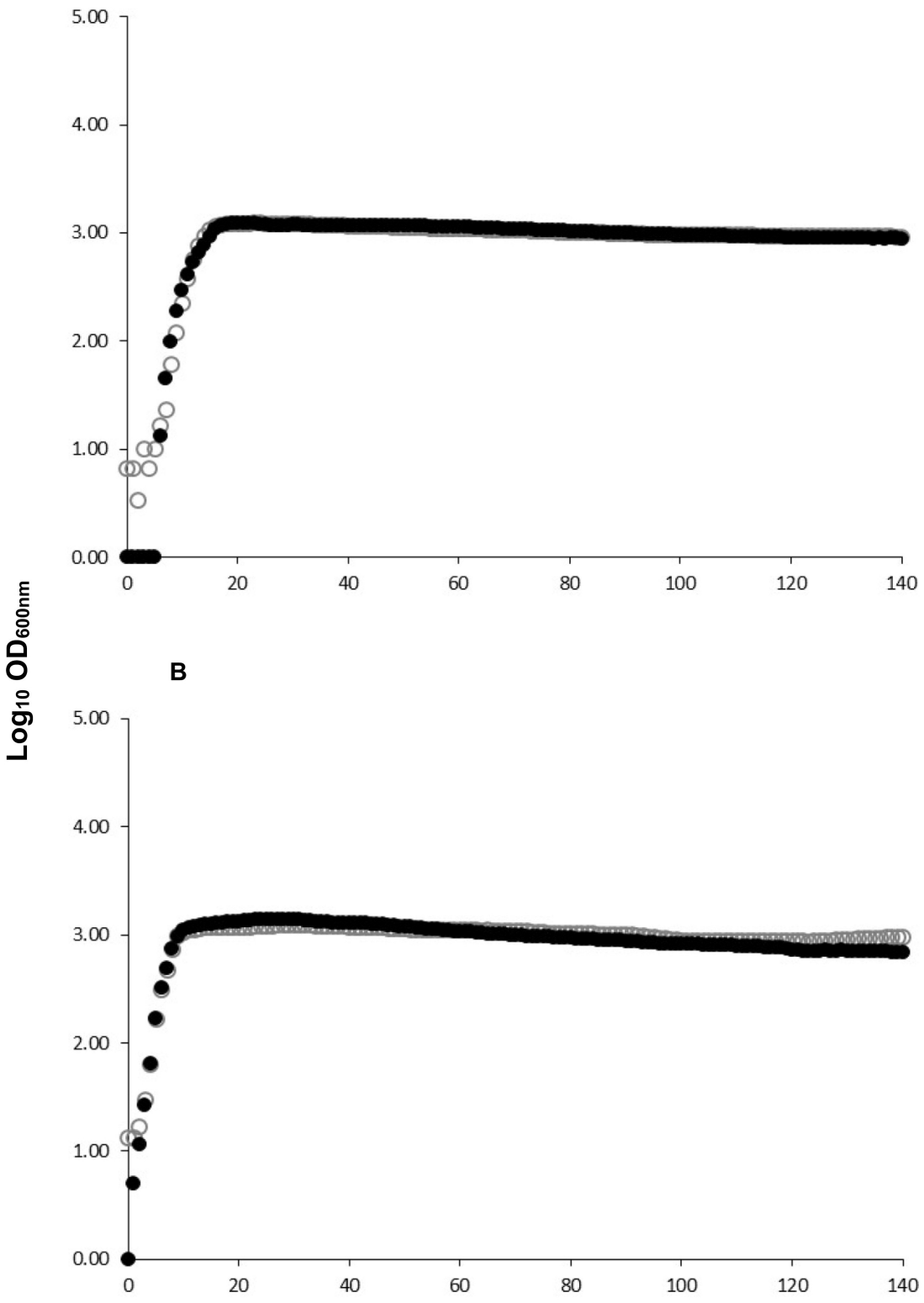

Time (h)

Figure 1 
A

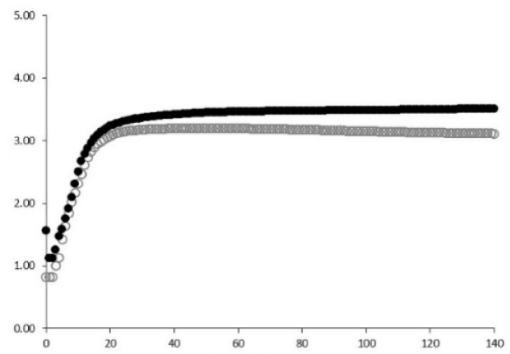

D

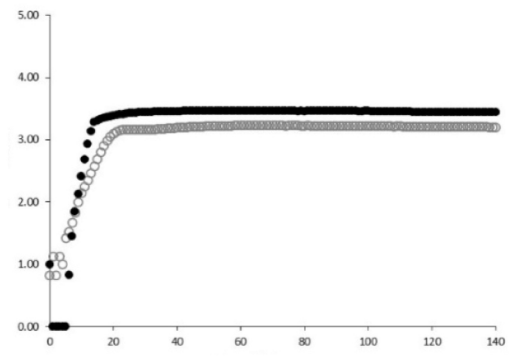

G

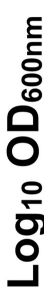

B

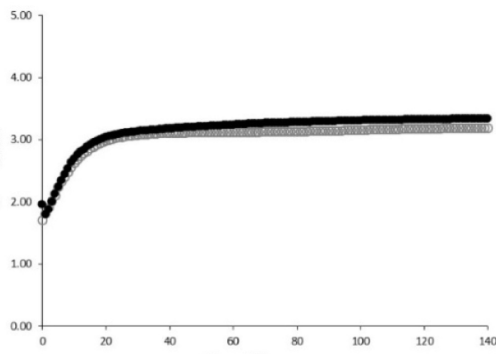

E

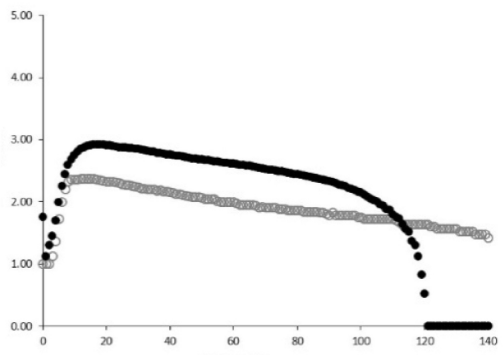

H

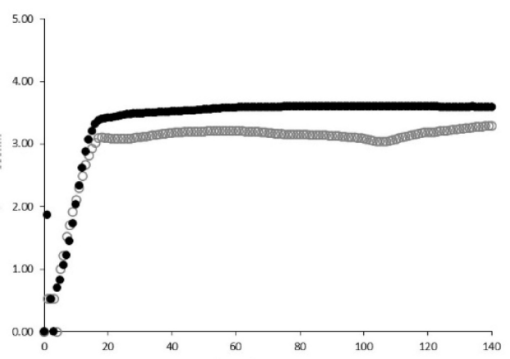

K

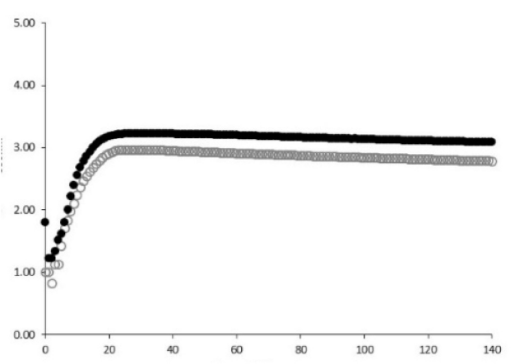

$\mathbf{N}$

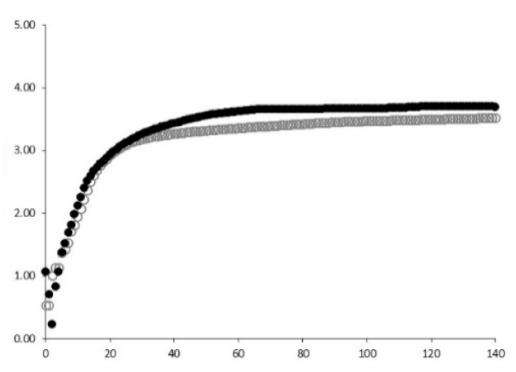

Time (h)
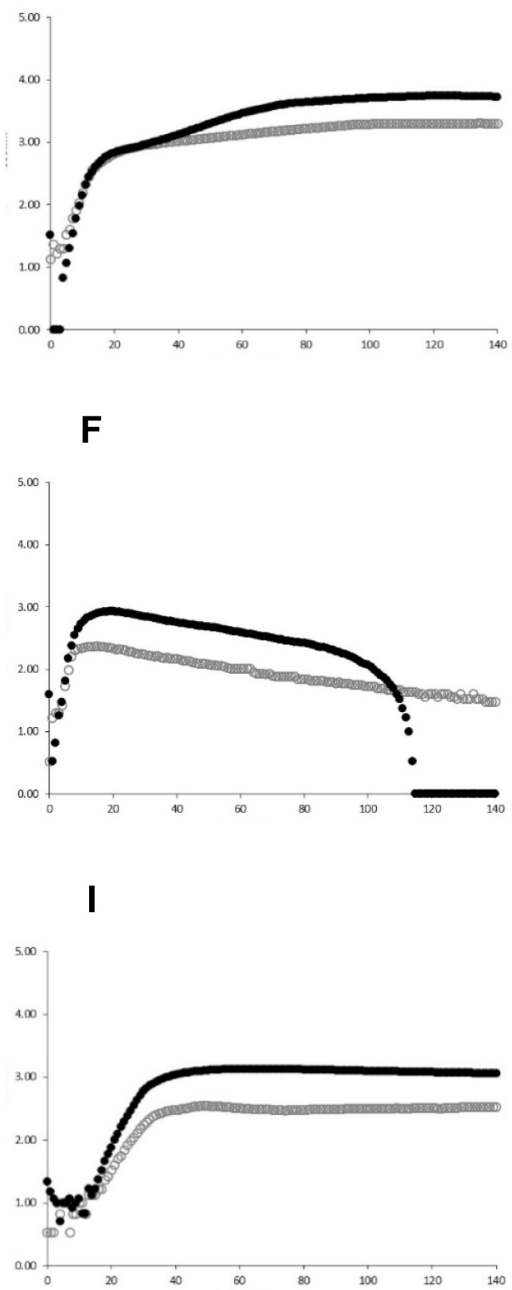

L

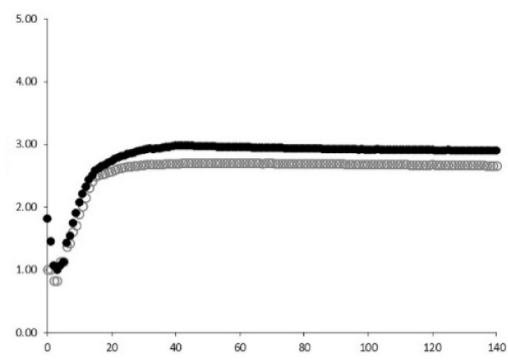

0

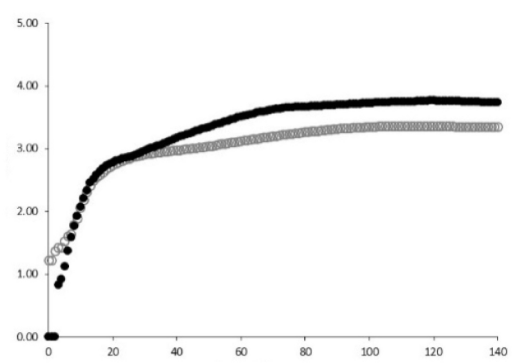

Figure 2 
A

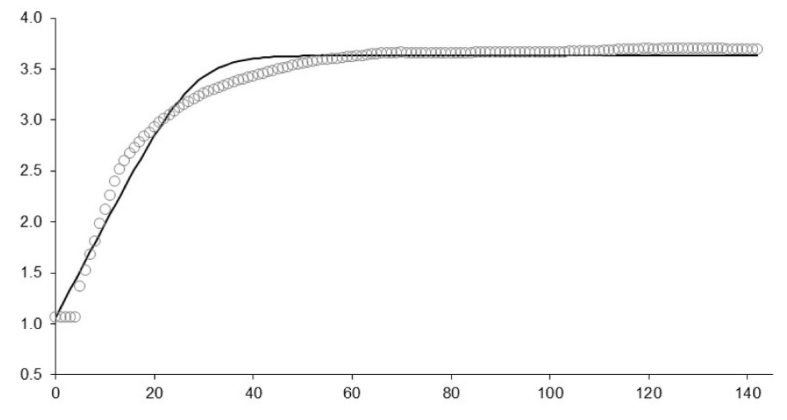

C

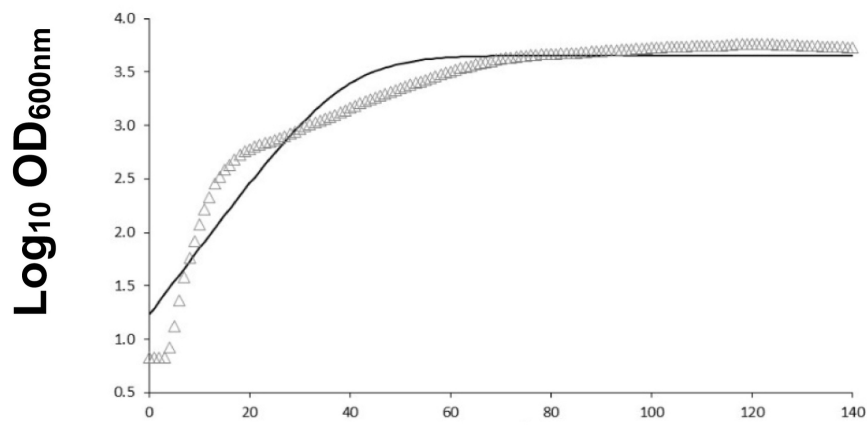

E

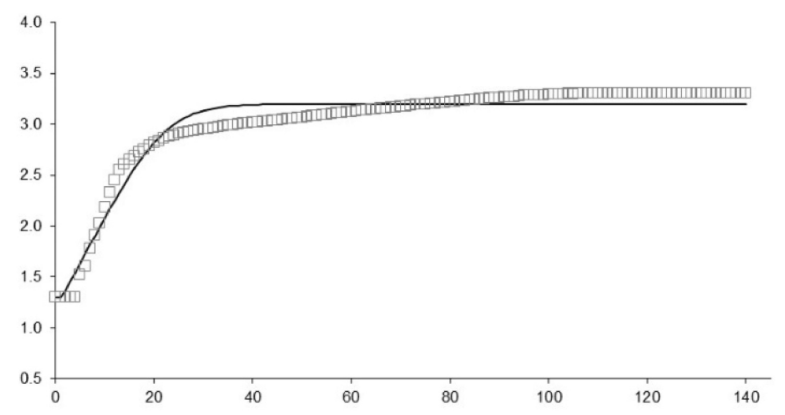

B

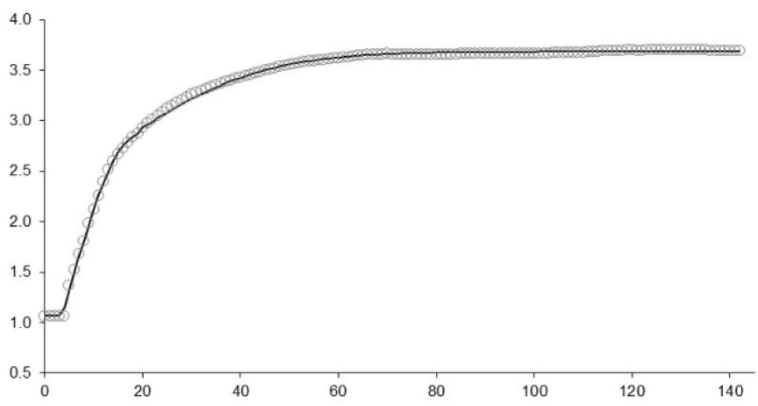

D

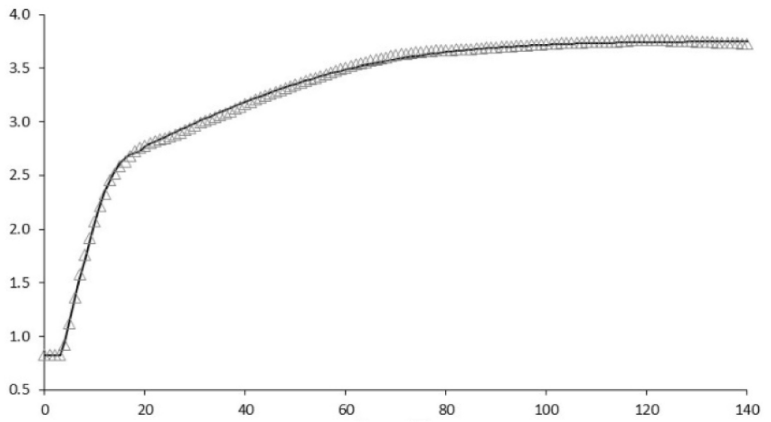

F

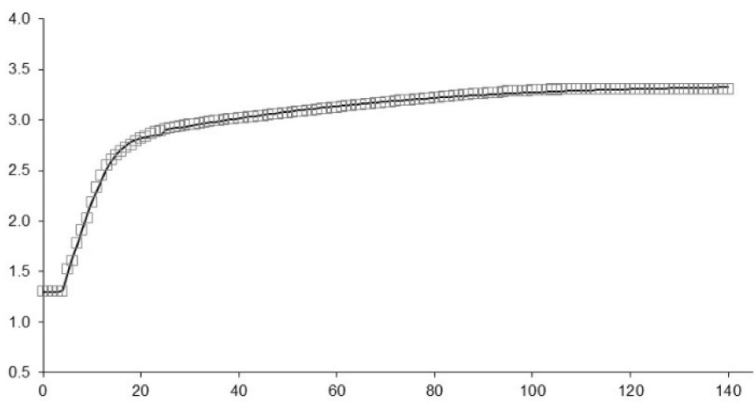

Time (h) 

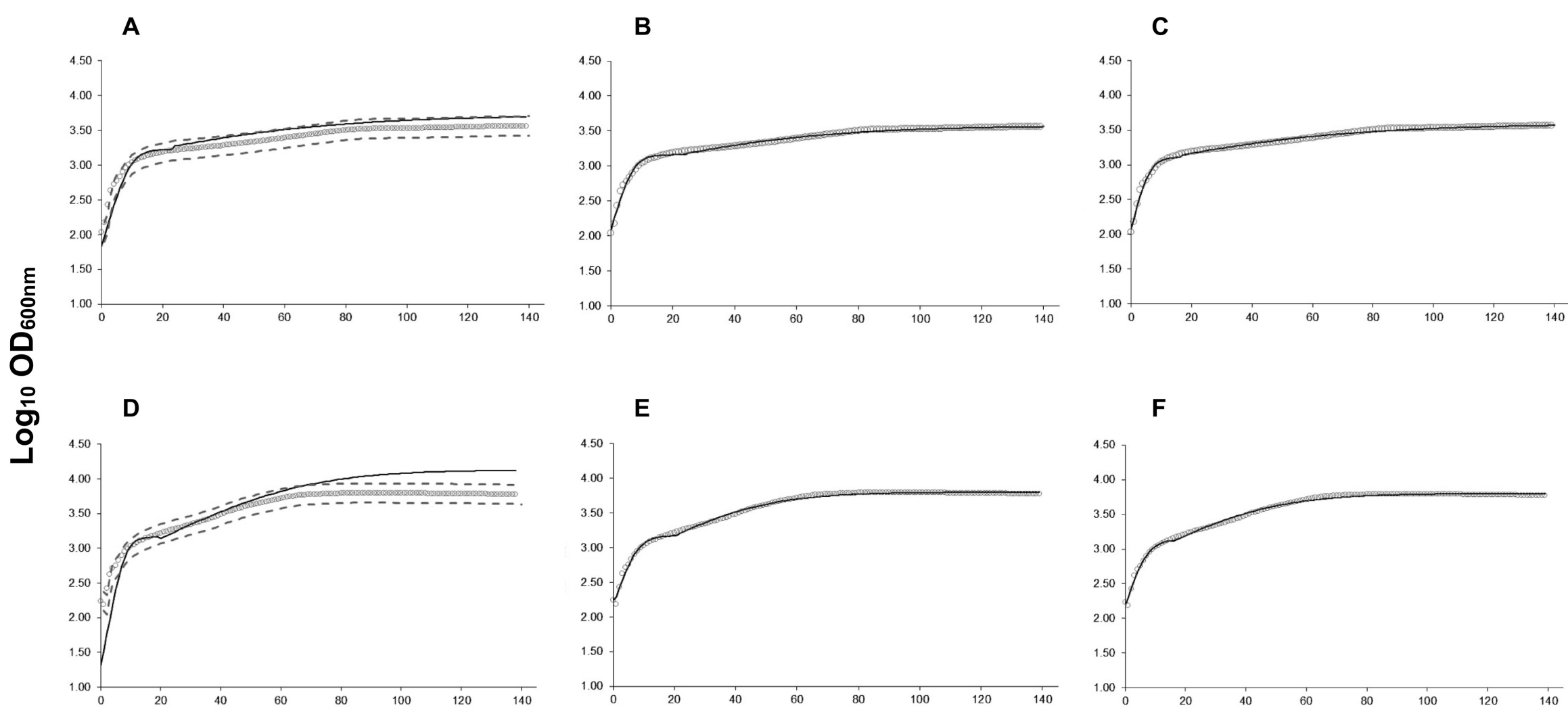

Time (h) 


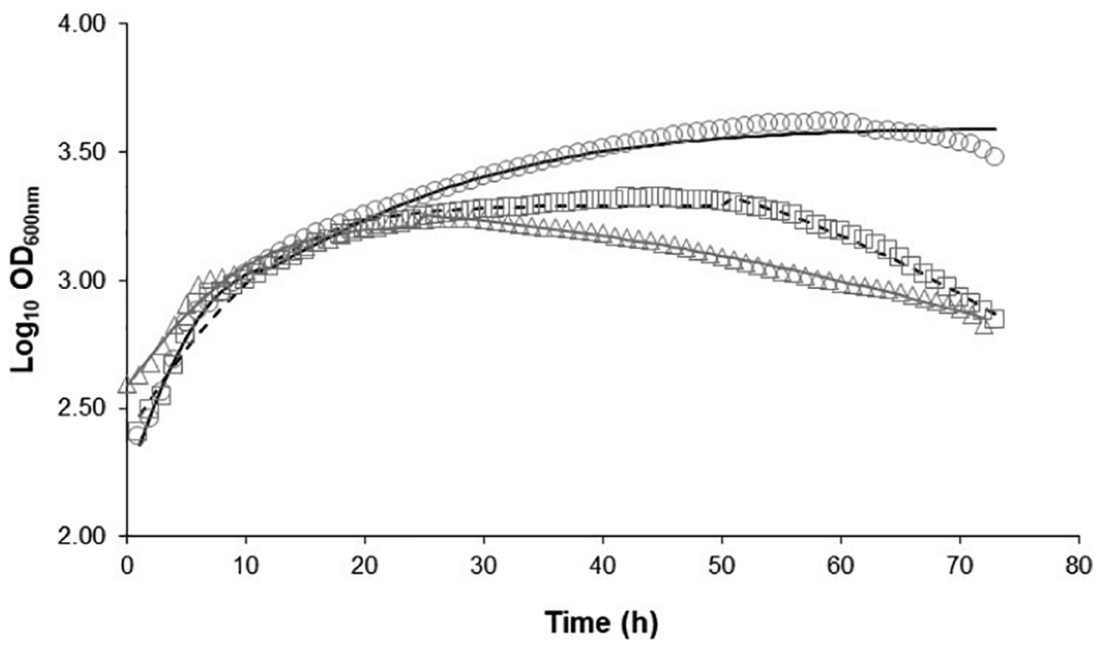

Figure 5 


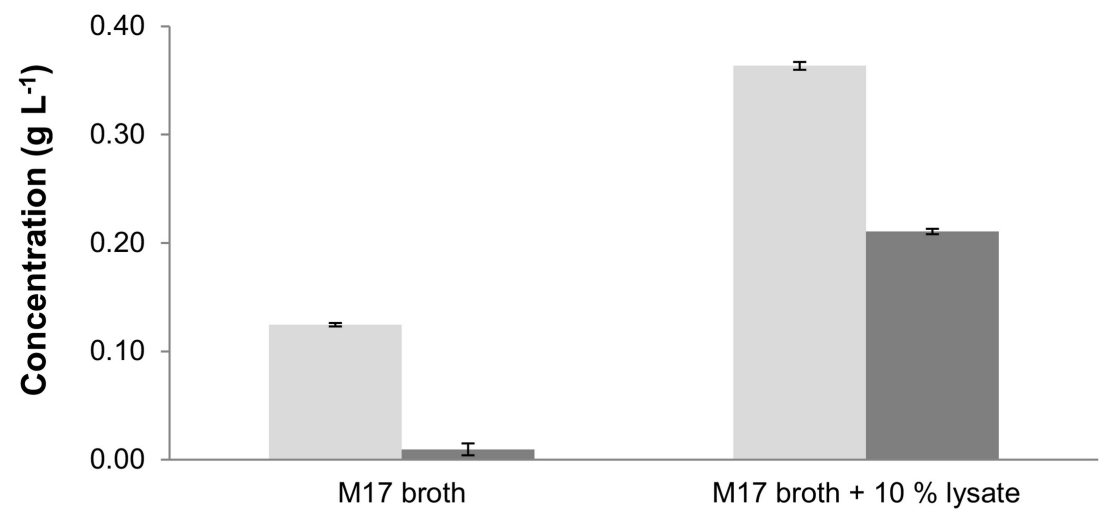

\section{Sample ID}

Figure 6 

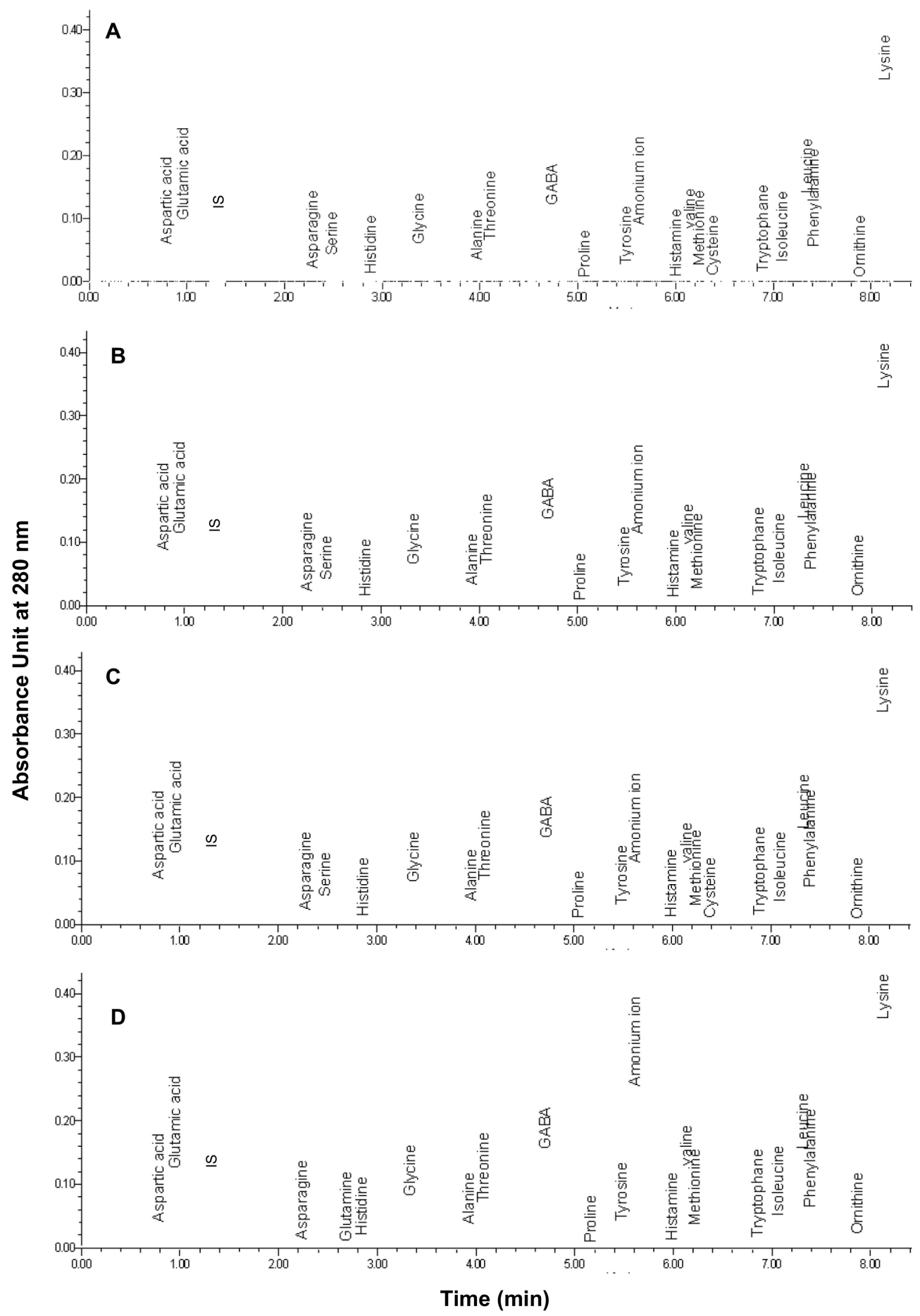

Figure 7 